\title{
歳差運動ならびに回転運動をする円柱まわりの流れの 数值シミュレーション*
}

\author{
尾 形 秀 樹*1, 赤 松 映 明*2, 新 谷 昌 孝*3
}

\author{
Numerical Flow Simulation for Nutating Motion \\ and Rotating Motion of Circular Cylinder
}

\author{
Hideki OGATA, Teruaki AKAMATSU and Masataka SHINTANI
}

\begin{abstract}
Unsteady incompressible viscous flows generated by nutating motion and rotating motion of a circular cylinder are analyzed numerically by the discrete vortex method with viscous diffusion model proposed by Ohgami and Akamatsu. This method is applied to the rotational coordinates. The calculation is executed for Reynolds numbers $R e=50,1000$ and radii of orbit $R=3 a, 0.9 a, 0.32 a$ ( $a$-aradius of the circular cylinder). Stream lines show that the rotating cylinder imparts to the fluid stronger motion than the nutating cylinder. The calculated force indicates that the hydrodynamic force caused by the fluid viscosity is directed toward the center of the orbit.
\end{abstract}

Key Words: Computational Fluid Dynamics, Unsteady Flow, Viscous Flow, Circular Cylinder, Nutating Motion, Rotating Motion, Discrete Vortex Method, Viscous Diffusion Model

\section{1. 緒言}

川柆の藏差連動（公転）と回転運動（公転十自転）は ともに単純な速動様式であるにもかかわらず,これら つ流れの差異も令めてその特性は明かでない. 歳差運 動は藏等式邀心向液ボンプや，波浪水面下の水平円柱 (水快没水㤔柱) (1).(2)まわりの流れに特徽的な運動で あり、それぞれの分野で研究がなされている。

本研究ではこれらを单純化, つまり藏差式遠心血液 ホンクののーシングや水斗没水门柱の水面の影響を除 いた連動として，次元無限領域内で円軌道を描きな がら藏筷運動（すりこざ連動）ならびに回転運動を開 始する们柱のまわりの非非縮・非定常粘性流れを，粘 性执散モデルを用いた雖散渦法 (3)によって計算する。 まず。この方法を回転座標系に適用する方法を示した

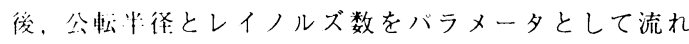
の数做解析老行う。

なお，句算に用いる㒕散瀜法は流九場に格子を形成 す为必装がなく，本研究のような二次元無限領域内の 流九を解析するのに適している。また，粘性の効果を

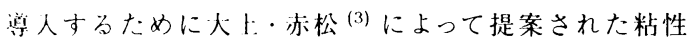
报散モデルは、新谷・赤松(4).(5)によって具体的な問題 に適用する西法が提ホされ，最近，大上ら(6)は類似の 手法で川柱まわりの流机の尌算を行なっている。従来

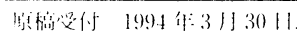

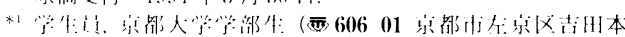
(Hi).

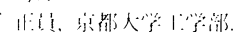

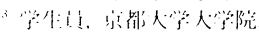

の離散渦法と比べた本計算方法の特徽については文献 (3)ー(7)を参照していただきたい。

\section{2. 計算方法}

$2 \cdot 1$ 粘性拡散モデルを用いた離散渦法粘性拡 散モデルを用いた離散渦法の詳細な説明とその手順に ついては文献 $(3) \sim(5)$ に示されており,ここでは簡単 にふれておく.

まず物体表面を N 分割し，流れが物体表面を貫かな いという境界条件, および総循環がゼロというケルビ ンの循環定理により, 各表面要素で生成される離散渦 の大きさを決定する。 $i$ 番目の離散渦を中心位置 $\left(\xi_{i}, \eta_{i}\right)$, 循環 $\Gamma_{i}$, 渦コア半径 $\delta_{i}$ のガウス型の渦度分布で表わす と, 任意の点 $(x, y)$ での渦度 $\omega$ は,

$$
\omega=\sum_{i} \frac{\Gamma_{i}}{\pi \delta_{i}} \exp \left\{-\frac{\left(x-\xi_{i}\right)^{2}+\left(y-\eta_{i}\right)^{2}}{\delta_{i}^{2}}\right\}
$$

となる。

ところで渦度の輸送方程式

$$
\frac{\partial \omega}{\partial t}+\boldsymbol{u} \cdot \nabla \omega=\nu \nabla^{2} \omega \quad \nu \text { : 動粘性係数 }
$$

は $\boldsymbol{u}_{d}=-\nu \nabla \omega / \omega て ゙$ 定義される粘性拡散速度を用いる ことにより,

$$
\frac{\partial \omega}{\partial t}+\nabla \cdot\left\{\left(\boldsymbol{u}+\boldsymbol{u}_{d}\right) \omega\right\}=0
$$

と書き換えられる。この式は速度 $\left(\boldsymbol{u}+\boldsymbol{u}_{d}\right)$ で移動する 閉曲線に沿って循環が保存されることを示している。 


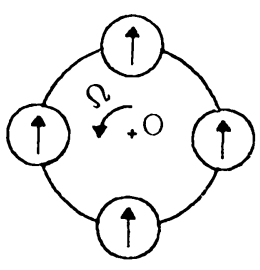

Nutating motion

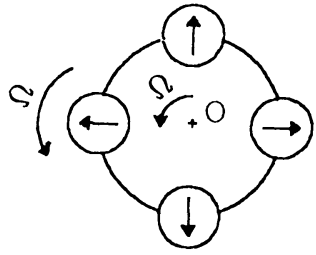

Rotating motion
Fig. 1: Nutating motion and rotating motion

したがって物体表面から放出された蜼散渦を，その循 環を一定にしたまま距蜼 $\left(\boldsymbol{u}+\boldsymbol{u}_{d}\right) \Delta t$ ( $\Delta t$ : 時間刻み幅) だけ移動させることで粘性流れが表現できる。

蜼散渦を移動させた後，再び境界条件とケルビンの 定理に従って表面で生成される渦を決定し，以後これ らを繰り返しながら時刻を進めていく。

これが粘性拡散モデルを用いた蜼散渦法の概略であ ク，剥蜼点の設定などの特別な配虑を必要とせずに境 界層の発達や剥蜼現象を扱うことができる。

\section{$2 \cdot 2$ 歲差通動と回轱通動歳差運動と回転運動の} 様子をFig. 1に示す. 歳差運動は点 $\mathrm{O}$ に対して公転（角 速度 $\Omega$ )のみを行なっているのに対し，回転運動はさ らに同じ角速度の自転も加わっている。

円柱表面上の境界条件は, 両運動ともに流体が物体 表面を貫かないことは共通しているが，接線方向の 速度を異にしている。そこで次のように考えることに よって歳差運動と回転運動を区別して表現することが できる。

回転運動の場合，角速度 $\Omega$ で自転している円柱はそ の内部領域に一様な渦度 $2 \Omega$ を持つ流体で置き換える ことができる。さらにこの渦度が円柱表面に接する流 体に及ほすす影響は，円柱の中心においた反時計まわり 方向の循環 $\Gamma_{0}=2 \pi a^{2} \Omega \quad(a$ :円柱の半径）によるものと 等しい，すなわち自転する円柱と循環 $\Gamma_{0}$ とは等価で ある。一方歳差運動ではこのような循環を置く必要は ない.

したがってある時刻までに物体表面上の渦層ならび に表面から放出された渦による総循環を $\sum_{i} \Gamma_{i}$ とする と, 静止状態から出発した流れに対してケルビンの循 環定理は,

$$
\begin{aligned}
& \text { 歳差運動 }: \sum_{i} \Gamma_{n i}=0 \\
& \text { 回転運動 }: \sum_{i} \Gamma_{r i}=-\Gamma_{0}
\end{aligned}
$$

となる。ここに添字 $n$ および $r$ はそれぞれ歳差運動お よび回転運動を表わす。
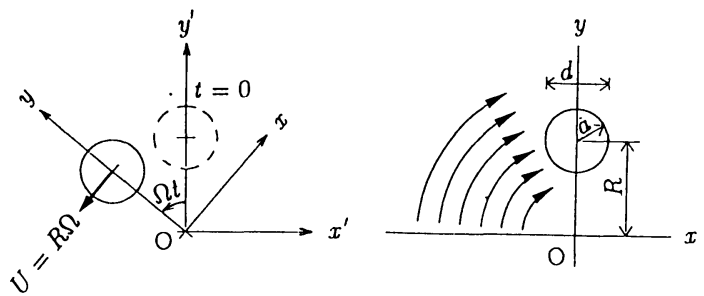

Stational coordinates $\left(x^{\prime}, y^{\prime}\right) \quad$ Rotational coordinates $(x, y)$

Fig. 2: Coordinates

次節で述べるように本計算は回転座標系で行なう。 運動開始前の静止状態は回転座標系では流体・円柱と もに角速度 $-\Omega$ で自転している状態にある。運動開始 後, 円柱は見かけ上, 回転運動では静止状態に変わり, また，歳差運動では角速度 $-\Omega の$ 自転を続けたままで ある。したがって運動を開始した瞬間に円柱表面上に 発生する渦層のもつ総循環は回転運動では $-\Gamma_{0}$, 葴差 運動では零である。

$2 \cdot 3$ 座槙系計算は静止座標系 $\left(x^{\prime}, y^{\prime}\right)$ に対して 角速度 $\Omega$ で回転する座標系 $(x, y)$ で行なう(Fig. 2$)$ )。こ の座標系では円柱は公転せずに，一様な渦度 $-2 \Omega$ を持 つ流体の中にある。

回転座標系での連続の式とナビエ・ストークスの式 は $\rho, p$ をそれぞれ流体の密度, 压力とすると，

$$
\begin{aligned}
\nabla \cdot \boldsymbol{u}= & 0 \\
\frac{\partial \boldsymbol{u}}{\partial t}+(\boldsymbol{u} \cdot \nabla) \boldsymbol{u}= & -\frac{1}{\rho} \nabla p+\nu \nabla^{2} \boldsymbol{u} \\
& -\boldsymbol{\Omega} \times(\boldsymbol{\Omega} \times \boldsymbol{r})+2 \boldsymbol{u} \times \boldsymbol{\Omega}
\end{aligned}
$$

となる。ただし $, \boldsymbol{r}=(x, y, 0), \boldsymbol{\Omega}=(0,0, \Omega)$ である。ナ ビエ・ストークスの式には遠心力 $-\boldsymbol{\Omega} \times(\boldsymbol{\Omega} \times \boldsymbol{r})$ とコリ オリの力 $2 \boldsymbol{u} \times \Omega$ が現われている。しかし $\boldsymbol{r}$ および $\Omega$ がそれぞれ $x, y$ 方向成分扰よび $z$ 方向成分しか持たな いことに注意してこれらの rotをとるといずれも零に なる。したがって式(7)の rotをとると，

$$
\begin{gathered}
\frac{\partial \omega}{\partial t}+(\boldsymbol{u} \cdot \nabla) \omega=\nu \nabla^{2} \omega \\
\therefore \quad \frac{\partial \omega}{\partial t}+\nabla \cdot\left\{\left(\boldsymbol{u}+\boldsymbol{u}_{d}\right) \omega\right\}=0 .
\end{gathered}
$$

すなわち回転座標系でも速度 $\left(\boldsymbol{u}+\boldsymbol{u}_{d}\right)$ で移動する閉曲 線に沿って循環が保存される。

ところで回転・静止両座標系での渦度 $\omega, \omega^{\prime}$ の間 には，

$$
\omega=\omega^{\prime}-2 \Omega
$$

なる関係が成立する，静止座標系に関する式(2)および

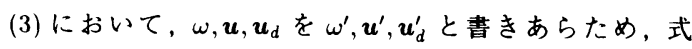



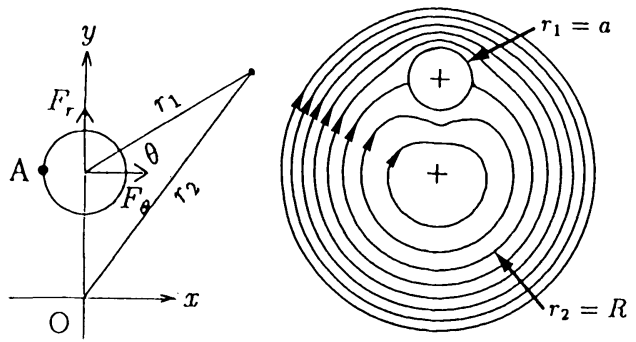

Fig. 3: Inviscid flow viewed from rotating coodinates

(10)の関係を式 (8) または (9)に代入すると各項は

$$
\begin{aligned}
\nabla \cdot(\boldsymbol{u} \omega) & =\nabla \cdot\left(\boldsymbol{u} \omega^{\prime}\right) \\
\nabla \cdot\left(\boldsymbol{u}_{d} \omega\right) & =\nabla \cdot\left(\boldsymbol{u}_{d}^{\prime} \omega^{\prime}\right) \quad\left(\boldsymbol{u}_{d}^{\prime}=-\nu \frac{\nabla \omega^{\prime}}{\omega^{\prime}}\right)
\end{aligned}
$$

と書き換えられ，

$$
\frac{\partial \omega^{\prime}}{\partial t}+\nabla \cdot\left\{\left(\boldsymbol{u}+\boldsymbol{u}_{d}^{\prime}\right) \omega^{\prime}\right\}=0
$$

と変形できる.

ここで式 (9)と式(13)のもつ意味を考えてみる。式 (9)は先に述べたように，回転座標系上で速度 $\left(\boldsymbol{u}+\boldsymbol{u}_{d}\right)$ で移動する閉曲線に沿って循環が保存されることを示 している。この循環のうち蜼散渦による静止座標系上 での寄与を「とし，またこの閉曲線が囲む面積を $\mathrm{S}$ と すると，回転座標系での速度 $\left(\boldsymbol{u}+\boldsymbol{u}_{d}\right)$ に対して保存さ

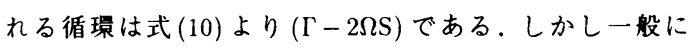
$\operatorname{div} \boldsymbol{u}_{d} \neq 0$ であるのでこの面積 S は流れとともに変化 し、したがって蜼散瀜による循環「は保存されない。こ れでは蜼散渦の循環が保存されるという粘性拡散モデ ルの利点が生かされない.しかし式(13)は速度 $\left(\boldsymbol{u}+\boldsymbol{u}_{d}^{\prime}\right)$ で蜼散渦を移動させることによってその蜼散渦の循環 「が保存されることを示しており，実際の計算ではこ ちらを用いるほうが便利である。

2.4 非粘性解析 円柱が非粘性の静止流体中で円 軌道を描くときの流れは解析的に解くことができる.

いま，回転座標系からみて次の流れ関数 $\psi$ で表わさ れる流れを考える (Fig. 3)；

$$
\psi=\frac{\Omega}{2} r_{2}^{2}-\frac{\Omega R a^{2} \sin \theta}{r_{1}} .
$$

これは一様な渦度 $-2 \Omega$ の中に強さ $\Omega R a^{2}$ の二重吹出し がある流れであり，流線をFig.3に示す。この流れを静 止座標系からみれば二重吹出しのみが円軌道を描いて いる非定常ポテンシャル流れである.

ここで $\psi=\Omega\left(R^{2}+a^{2}\right) / 2$ とおくと一つの流線は $r_{1}=a$ および $r_{2}=R$ となる。これより $r_{1}=a$ なる円柱壁が正 しく形成されていることがわかる。また円柱表面に沿 う速度 $u$ を求めると次のようになる；

$$
u=-\frac{\partial \psi}{\partial r}=-\Omega(a+2 R \sin \theta) .
$$

Table 1: Conditions of computation

\begin{tabular}{|lc|c|c|}
\hline & & $R e=1000$ & $R e=50$ \\
\hline$R / a=3$ & $(\Omega \Delta t=0.06 \mathrm{rad})$ & Case 1 & Case 2 \\
\hline$R / a=0.9$ & $(\Omega \Delta t=0.15 \mathrm{rad})$ & Case 3 & Case 4 \\
\hline$R / a=0.32$ & $(\Omega \Delta t=0.30 \mathrm{rad})$ & Case 5 & Case 6 \\
\hline
\end{tabular}

まず，粘性のない場合について円柱に作用する流体 力を求めておこう. そのためにベルヌーイの式を用い て円柱表面の圧力を計算する．回転座標系でみている のであるから流体には遠心力とコリオリの力が働き， それぞれの単位体積あたりのポテンシャルエネルギ $\phi_{1}$ および $\phi_{2}$ は表面上で，

$$
\phi_{1}=-\frac{\Omega^{2}}{2} r_{2}^{2} \quad, \quad \phi_{2}=2 \Omega \psi=\text { const. }
$$

となる。これらを用いると, 一つの流線である円柱表 面に対してベルヌーイの式

$$
\frac{u^{2}}{2}+\frac{p}{\rho}+\phi_{1}+\phi_{2}=\text { const. }
$$

が成立する。これに式(15), (16)を代入すると, 図 3 の 点 $\mathrm{A}$ を基準とする圧力係数 $C_{p}$ は,

$$
C_{p}=\frac{p-p_{A}}{\frac{1}{2} \rho U^{2}}=-4 \sin ^{2} \theta-\frac{2 a}{R} \sin \theta \quad(U=R \Omega)
$$

となる。ささらFig.3に示すように流体力 $F_{r}, F_{\theta}$ をとり, $\rho U^{2} d / 2$ で無次元化してそれぞれ $C_{r}, C_{\theta}$ とすると, 圧 力係数 $C_{p}$ を円柱表面上で積分することにより,

$$
C_{r}=\frac{\pi a}{R} \quad, \quad C_{\theta}=0
$$

を得る。

$2 \cdot 5$ 計算条件 円柱が静止流体中で突然運動し 始める場合について計算を行なう。計算条件は歳差 運動および回転運動を 1 対として，表 1 に示すよう に公転半径 $R$ と円柱半径 $a$ の比 $R / a$, レイノルズ数 $R e=U(2 a) / \nu$ を与えて計 6 対に対して行なった( case 1 6).ここに代表速度 $U=R \Omega$ である. 特に case $3 \sim 6$ は公転中心が円柱の内部にある時の運動である。

なお, 本計算では離散渦のコア半径 $\delta_{i}$ は渦間隔に比 例させて広げ，またサブエレメント法(4),(8)も用いた。

またすべての計算に対して共通した条件は，表面分 割数 $N=40$, サブエレメント数 $N_{s u b}=10$ である。.

\section{3. 結果と考察}

3・1 円柱の更峌菉式に基づく考察まず回転と 歳差, $R / a>1$ と $R / a<1$ の場合の流れの相違を説明 するに当たり，流れについての考察を加えておく.Fig. 4 は円柱表面上の点 $\mathrm{P}, \mathrm{Q}$ の移動の様子を示す. 藏差運 


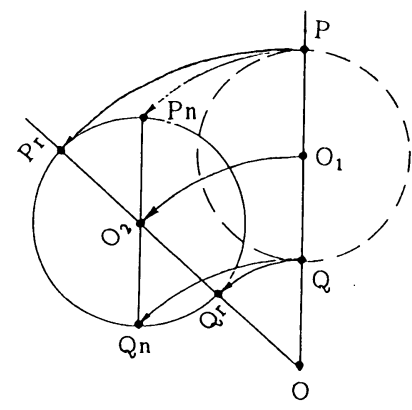

$R / a>1$

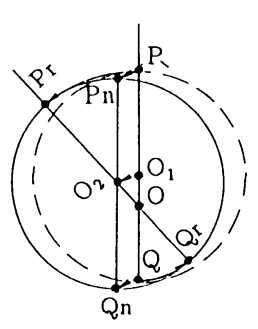

$R / a<1$
Fig. 4: Moving configuration of cylinder

動，回転運動によって点 $\mathrm{P}, \mathrm{Q}$ はそれぞれ点 $\mathrm{Pn}, \mathrm{Qn}$ お よび点Pr, Qrに移動する.

さて，運動初期の円柱表面上の境界層について考え る.まず $R / a>1$ の場合, 回転運動では点 $\mathrm{P}, \mathrm{Q}$ と点 $\mathrm{Pr}, \mathrm{Qr}$ は円柱の進行方向に対して角度 $90^{\circ}$ の位置にあ り，境界層はほほこれらの点で剥離を起こし渦として 後流中に放出されると考えられる。一方, 歳差運動で は旋回円柱上方の点 $\mathrm{Pn}$ は進行方向に対して背面とな ク, 点Pnの境界層はより一層容易に剥離を起こす. 円 柱下方の点Qnでの境界層は円柱の前面に廻し戻され て円柱表面上に留まっており, 後流渦として放出され ない。つまり旋回円柱内側からの渦の放出は抑制され ると考えられる。

また $R / a<1$ の場合点 $\mathrm{Qr}$ が点 $\mathrm{Q}$ の後方に引き下が $\eta$, 円柱表面上に $R / a>1$ の場合とは逆の方向の渦の 生成を助長することになる。

$3 \cdot 2$ 渦点分布と流楾 円柱表面から放出された 離散渦の分布の代表例をFig.5に示す. 渦の正負を赤と 青で区別して表しており，上述の考察通りの渦の生成 が見られる。 $R e=50$ の渦点の分布は拡散が著しく, 渦列としてのパターンは明瞭ではない.

ここではとくに case 1 と case 5 に注目してみる。ま ず case 1 を見ると, 円柱の上部,下部から交互に渦塊 が放出されている。しかし歳差運動 $(\mathrm{N})$ では円柱下部 から放出された正の渦 (赤) が回転運動 $(\mathrm{R})$ に比べて その占める領域は狭い。これは $3 \cdot 1$ 節で述べたように， 歳差運動では円柱下部での剥離が抑制されているため である。次に case 5 を見ると歳差運動では円柱上部は 剥離が生じ易く, 放出された渦（青）は広い領域を 占め波打っており, 一方の下部で生成された渦は円柱 表面にまとわりついて放出されていないことが観察さ れる。

Fig. 6 は case 1 と case 5 に対する静止座標系での流線で
ある. Case 1 では渦点分布でも見られた正負交互の渦 が $\mathrm{A} ， \mathrm{~B} ， \mathrm{C} の$ 順に放出されている。また上で述べたよ うに歳差運動では 2 番目に放出された正の渦 B は弱く, またFig.5, 6 の case 1 をみると歳差運動の方が後流渦の まわり込みが早いことがわかる．

Case 5 は $R / a<1$ の流れである. 他の $R / a<1$ の流れ も定性的にこれと同じであり，時刻が進むにつれて同 心円状の流線群が形成されていくのが観察される。流 体が非粘性の場合， $2 \cdot 4$ 節で述べたように円軌道を描 く円柱は二重吹出しで表現できるので, 運動の初期は 粘性のある場合でも二重吹出し流れに類似している。 その後粘性の影響で流体は円柱に引きずられてこのよ うな旋回流れになる。各時刻における流線を観察した 結果, case 3 6にみられる同心円状の流線群が現れる のは回転角がおよそ $400^{\circ}$ の時であることがわかる。ま た流線の間隔をみると, 回転運動の方が歳差運動より も強い旋回流れが発生していることがわかる。このこ とと case 1 の回転運動でのみ正の渦 B が認められたこ ととから, 回転運動の方が歳差運動よりも激しい運動 を流体に与えるといえる。これは回転運動には円柱の 自転が加わっていることを考えるとうなずける．

$3 \cdot 3$ 速度变化二重吹出し流れから旋回流れへの 移行を確認するために, 回転座標上で円柱の上方 $a / 2$ の点において $x$ 方向の速度成分の時間変化を調べた。 Fig. 7 は Case 3,4 についてこの点の静止座標系に対する 無次元化流速 $u / U$ の時間経過を示している.式(14)の 非粘性流れの二重吹出しの項のみをみると， $r_{1}=1.5 a$, $\theta=\pi / 2$ の位置での流速は $u / U=0.44$ である.旋回流 れが形成されるにしたがって $u / U$ は正から負の方向に 変わる. $400^{\circ}$ 付近から負, すなわち円柱の進行方向に 速度を持つようになる. 円柱から放出された渦点の分 布を確認した結果、これは最初に放出した渦が再び円 柱にふつかる時刻にほほ対応することがわかる。これ はまた同心円状の流線が現れ始める時刻でもある。

これらの速度変化の様子は次のように解釈すること ができる。時刻ゼロの瞬間は流れは非粘性と考えられ るから上で示したように 0.44 となるが，しだいに円柱 に引きずられてその値を隇じる，回転角が $400^{\circ}$ 付近に 達するとはじめに放出した負の渦と衝突し, 円軌道の 外側に負の渦度場が形成される。これによって円柱の 近くでは円柱の進行方向への速度が誘起される.

\section{4. 結論}

計算を行なうにあたり，まず粘性拡散モデルを用い た離散渦法の回転座標系への適用方法を示した。計算 によって得られた知見は以下の通りである， $R / a=3$, 


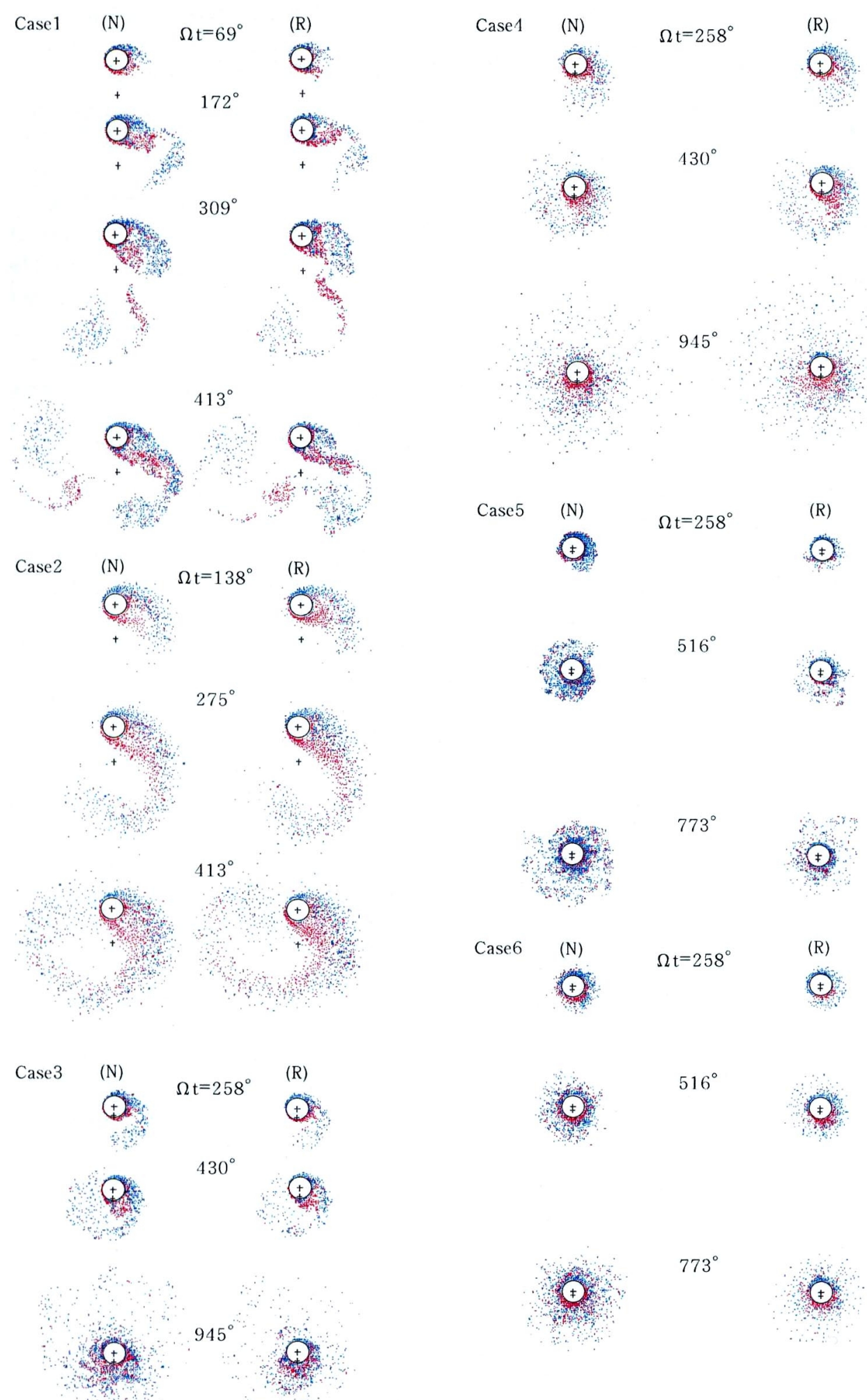

Fig. 5 : Distributions of discrete vortices $(\mathrm{N})$; Nutating motion, $(\mathrm{R})$; Rotating motion 


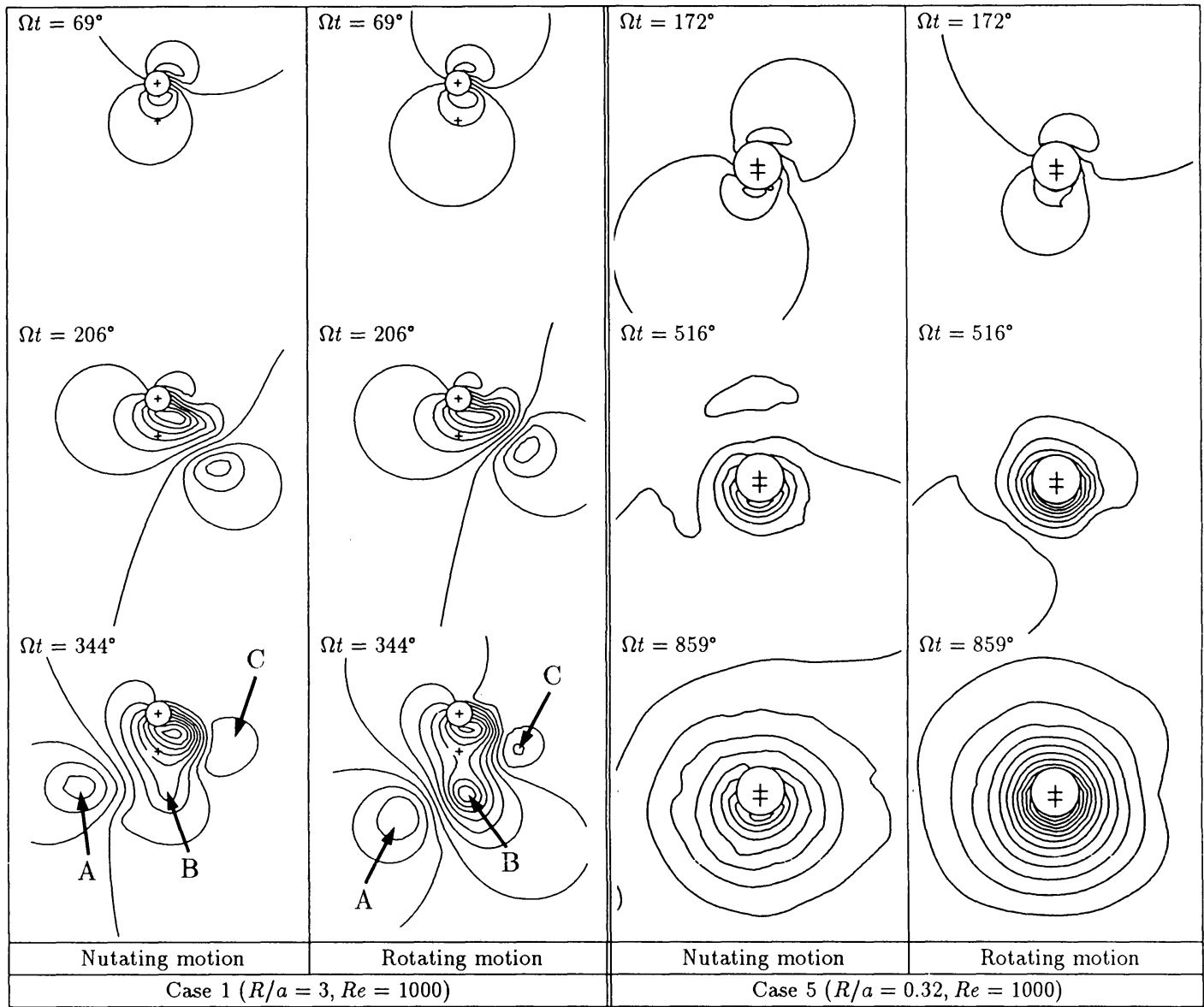

Fig. 6: Stream lines on the stational coordinates for Case 1 and Case 5



$$
\begin{array}{cc}
R e=1000 & R e=50 \\
- \text { Nutation } & --- \text { Nutation } \\
--- \text { Rotation } & -\cdots-\text { Rotation }
\end{array}
$$

Fig. 7: Variations of $x$-directional non-dimensional velocity $\mathrm{u} / \mathrm{U}$ at the position $(0,1 . \dot{5} \mathrm{a})$
$R e=1000$ の流れにおいて歳差運動と回転運動の渦の 出方に、剥離の違いによる顕著な差がみられた。また $R / a<1$ の流れでは，円柱が約 $400^{\circ}$ 回転すると同心円 状の流線群が現れ始めた。その流れは藏差運動よりも 回転運動の方が速い。総じて，回転運動の方が歳差運 動よりも激しい運動を流体に加えるといえる。なお Fig. 5の色付け作業に協力願った和田雄一郎君に謝意を 表す.

\section{文献}

（1）大塚 ·池田，関西造船協会誌, 213, (平 2), 177-186。

(2) 大塚 ·池田, 関西造船協会誌, 219, (平4), 135-141。

(3) 大上·赤松, 機論, 54-505, B(昭 63), 2283-2290.

(4) 新谷·赤松, 機論, 60-572, B(平 6), 112-19.

(5) M. Shintani and T. Akamatsu, Comp. Fluid Dyn. J., 3-2, (1994), 237-254.

（6）大上 $\cdot$ 綾野・藤原 $\cdot$ 細川，機論, 61-582, B(平 7), 372-378

(7) 大上・藤原・細川, 機論, 57-544, B(平 3), 4092-4099.

(8) R. I. Lewis, Vortex Element Methods for Fluid Dynamic Analysis of Engineering Systems, Cambridge University Press, (1991),27-32. 